\title{
Electromagnetic Shielding Characteristics of Eco-Friendly Foamed Concrete Wall
}

\author{
Sung-Sil Cho, ${ }^{1}$ Jin-Man Kim, ${ }^{2}$ and Ic-Pyo Hong ${ }^{1}$ \\ ${ }^{1}$ Department of Information and Communication Engineering, Kongju National University, Cheonan 31080, Republic of Korea \\ ${ }^{2}$ Department of Architecture Engineering, Kongju National University, Cheonan 31080, Republic of Korea
}

Correspondence should be addressed to Ic-Pyo Hong; iphong@kongju.ac.kr

Received 8 February 2017; Revised 21 March 2017; Accepted 3 April 2017; Published 12 April 2017

Academic Editor: Luciano Tarricone

Copyright (C) 2017 Sung-Sil Cho et al. This is an open access article distributed under the Creative Commons Attribution License, which permits unrestricted use, distribution, and reproduction in any medium, provided the original work is properly cited.

The electromagnetic shielding characteristics according to the material composition of foamed concrete, which was manufactured to reduce environmental pollution and to economically apply it in actual building walls, were researched herein. Industrial byproducts such as ladle furnace slag (LFS), gypsum, and blast furnace slag (BFS) were added to manufacture foamed concrete with enhanced functionalities such as lightweight, heat insulation, and sound insulation. The electrical characteristics such as permittivity and loss tangent according to the foam and BFS content were calculated and measured. Free space measurement was used to measure the electromagnetic shielding characteristics of the actually manufactured foamed concrete. It was confirmed that electromagnetic signals were better blocked when the foam content was low and the BFS content was high in the measured frequency bands $(1-8 \mathrm{GHz})$ and that approximately $90 \%$ of the electromagnetic signals were blocked over $4 \mathrm{GHz}$.

\section{Introduction}

A number of users using a wireless service using a wireless communication system such as a wireless LAN and a Bluetooth in the $2.4 \mathrm{GHz} / 5 \mathrm{GHz}$ band and a mobile communication system using the $3 \mathrm{G}$ and LTE are rapidly increasing. In addition, as the IoT age approaches, spectrum management is required to efficiently use limited frequency resources. In particular, various efforts are being made to improve the communication environment of buildings where wireless service users are concentrated, such as department stores, apartments, and companies. Generally there is interference between the same or adjacent channels. Studies on a frequency selective shielding space $[1,2]$ and a spectrum management technique capable of forming a wide coverage area according to a user's demand in the indoor space have been actively carried out $[3,4]$.

Recently, in order to improve the communication performance of the indoor space, it is becoming more important to analyze the electrical characteristics and electromagnetic wave transmission characteristics of the building materials constituting the building. In 2000, Cuinas and Sanchez [5] measured the propagation characteristics of the indoor of the building by measuring the reflection and transmission characteristics of wood, red brick, and glass as building materials in the $5.8 \mathrm{GHz}$ band and measured the propagation characteristics of building materials for UWB channel modeling in 2003 [6]. Recently, to predict the signal coverage of $700 \mathrm{MHz} \sim 5 \mathrm{GHz}$ wireless signal using free space measurement method, the propagation attenuation characteristics of real buildings were analyzed [7] and the propagation characteristics of building floors, glass, and bricks in the tens of $\mathrm{GHz}$ band were performed [8-10]. In addition, in 2015 [11], the electromagnetic reflection characteristics of the new building material, the thickness variation $(10 \mathrm{~mm}-40 \mathrm{~mm})$ of the foamed concrete, and the type of foaming agent (vegetable, animal foam) were observed for the $2-18 \mathrm{GHz}$ frequency band. In this study, for the first time, electrical characteristics and electromagnetic transmission characteristics of eco-friendly foamed concrete that can be applied to various building materials such as flooring, wall, and roof material were analyzed.

Foamed concrete, which is manufactured by generating foam inside concrete, is lighter than ordinary concrete, is 


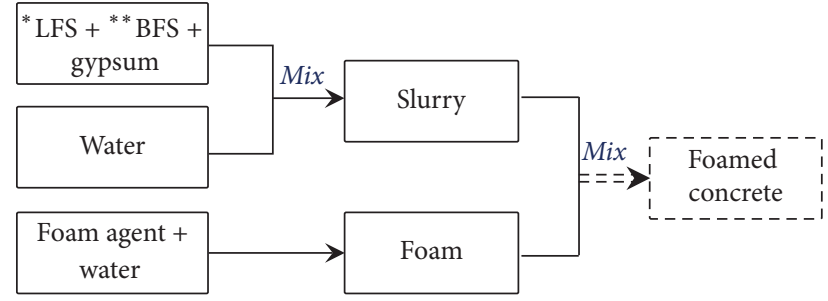

FIGURE 1: Manufacturing method of foamed concrete. ${ }^{*}$ LFS: ladle furnace slag. ${ }^{* *}$ BFS: blast furnace slag.

convenient to construct, has high heat insulation effect, and has outstanding sound absorption and insulation; however, it has the disadvantage of low durability due to which additional additives such as blast furnace slag (BFS), which is an industrial by-product, must be used for production to strengthen concrete $[12,13]$. BFS is a by-product that is created by finely splitting slag that is generated when producing pig iron with materials such as iron ore, coke, and limestone. Addition of BFS in concrete makes the material have large long-age strength, low hydration heat when water and cement react, and outstanding durability. In addition, it can reduce $\mathrm{CO}_{2}$ generation, reduce cement consumption because inexpensive industrial by-products are added in production, and lower manufacturing costs and it is used not only in foamed concrete, but also in ordinary concrete $[14,15]$. However, previous researches on concrete using BFS have used ordinary cement which generates $\mathrm{CO}_{2}$ and causes environmental pollution. Instead of using recent concrete, researches on concrete that can reduce environmental pollution by using industrial byproducts have been conducted $[16,17]$.

In this paper, we investigated the electromagnetic transmission of environmentally friendly foamed concrete walls by mixing industrial by-products with lightweight, fire resistance, heat insulation, and sound insulation effect. Ecofriendly foamed concrete was made by using industrial byproducts such as LFS (ladle furnace slag), gypsum, and BFS (blast furnace slag) instead of cement, and electrical properties were measured according to the content of foamed concrete and blast furnace slag. Using the measured electrical properties, the electromagnetic characteristics of echofriendly foamed concrete were simulated in the frequency range of $1 \sim 8 \mathrm{GHz}$ and the electromagnetic transmission characteristics were measured and analyzed using free space measurement method.

\section{Manufacturing of Foamed Concrete}

Various functions of the foamed concrete are determined using the content of foam and BFS; thus, the ratio of foam and BFS varies depending on the purpose of application. In this paper, foamed concrete wall material with $20 \%, 40 \%$, and $60 \%$ foam content and $0 \%, 20 \%, 40 \%$, and $60 \%$ BFS content was produced. As shown in Figure 1, LFS, gypsum, and BFS, which are the main materials of foamed concrete, were mixed in water to produce the slag. Foam created by using a vegetable foaming agent mixed with $4 \%$ water was mixed with the slag to manufacture the foamed concrete. After complete drying for expression of high strength of the produced foamed concrete, measurement tests in this paper were conducted to investigate the electromagnetic shielding characteristics.

\section{Electrical Properties of Foamed Concrete}

In general, the electrical properties of a material are different from each other depending on the material constituting the material and composition ratio and are defined as complex values such as $\varepsilon_{r}=\varepsilon_{r}^{\prime}-j \varepsilon_{r}^{\prime \prime}$. The dielectric constant and loss tangent are given by $\varepsilon_{r}^{\prime}$ and $\varepsilon_{r}^{\prime \prime} / \varepsilon_{r}^{\prime}$, respectively. The electrical properties are expressed as a function of frequency, and the amount of electromagnetic waves passing through or reflecting the material, that is, the transmission and reflection coefficients, is known through electrical properties [18]. The relationship between the dielectric constant of the material for the loss tangent and the transmission coefficient $T$ and the reflection coefficient $\Gamma$ is given by the following equation [1]:

$$
\begin{aligned}
T & =\frac{\left(1-\Gamma^{2}\right) \exp \left(-j k_{s} d_{s}\right) \exp \left(-\alpha d_{s}\right)}{1-\Gamma^{2} \exp \left(-j 2 k_{s} d_{S}\right) \exp \left(-2 \alpha d_{s}\right)} \\
\Gamma & =\frac{1-\sqrt{\varepsilon_{r}}}{1+\sqrt{\varepsilon_{r}}} \\
k_{s} & =\frac{2 \pi}{\lambda} \sqrt{\varepsilon_{r}} \\
\alpha & =\frac{\pi}{\lambda} \frac{\varepsilon_{r}^{\prime \prime}}{\sqrt{\varepsilon_{r}^{\prime}}}
\end{aligned}
$$

where $d_{s}$ is the thickness of the material and $\lambda$ is the wavelength. In general, the electrical properties of building materials are calculated from reflection and transmission characteristics measured in free space or reflection and transmission characteristics using coaxial cables $[1,19,20]$. In this paper, to analyze the electromagnetic transmission properties of environmentally friendly foamed concrete, we measured the permittivity and loss tangent by using coaxial cable measurement method and calculated the electromagnetic transmission characteristics. The calculated results were compared with the electromagnetic transmission characteristics measured by the free space measurement method. Table 1 shows the eco-friendly foamed concrete measured in this study.

3.1. Dielectric Characteristics Measurements of Foamed Concrete. In order to verify the foam content and the electrical properties according to the blast furnace slag content of the echo-friendly foamed concrete, the permittivity for a solid material having a flat surface with a thickness of more than $20 / \sqrt{\left|\varepsilon_{r}\right|}(\mathrm{mm}), \varepsilon_{r}$, and loss tangent $(\tan \delta)$ were measured repeatedly by calculating the degree of reflection by placing a measuring probe on the upper surface of the foamed concrete as shown in Figure 2. The N1501A, a dielectric 
TABLE 1: Experiment plan.

\begin{tabular}{|c|c|c|c|c|c|c|c|c|}
\hline \multirow{2}{*}{ Method } & \multirow{2}{*}{ Type } & \multicolumn{5}{|c|}{ Content rate $(\%)$} & \multirow{2}{*}{ Measurement } & \multirow{2}{*}{ Results } \\
\hline & & Foam & & & & & & \\
\hline \multirow{3}{*}{$\begin{array}{l}\text { Electrical } \\
\text { characteristics }\end{array}$} & \multirow{3}{*}{ Cylinder } & 20 & 0 & 20 & 40 & 60 & \multirow{3}{*}{$\begin{array}{l}\text { Coaxial cable } \\
\text { measurement }\end{array}$} & $\varepsilon$ \\
\hline & & 40 & 0 & 20 & 40 & 60 & & $\varepsilon_{r}$ \\
\hline & & 60 & 0 & 20 & 40 & 60 & & $\tan 0$ \\
\hline $\begin{array}{l}\text { Electromagnetic } \\
\text { transmission } \\
\text { characteristics }\end{array}$ & Panel & 20 & 0 & 20 & 40 & 60 & $\begin{array}{c}\text { Free space } \\
\text { measurement }\end{array}$ & $S_{21}$ \\
\hline
\end{tabular}

TABLE 2: Dielectric constant of materials sample.

\begin{tabular}{lccc}
\hline Materials samples & Size & Reference & Permittivity \\
& & 2.1 & Measured \\
\hline Teflon [22] & $40 \mathrm{~mm} \times 30 \mathrm{~mm} \times 20 \mathrm{~mm}$ & 2 & 2.04 \\
Wood (dry) [23] & $28 \mathrm{~mm} \times 28 \mathrm{~mm} \times 20 \mathrm{~mm}$ & 6 & 2 \\
Soda-lime glass [22] & $30 \mathrm{~mm} \times 30 \mathrm{~mm} \times 10 \mathrm{~mm}$ & 6.1 \\
\hline
\end{tabular}

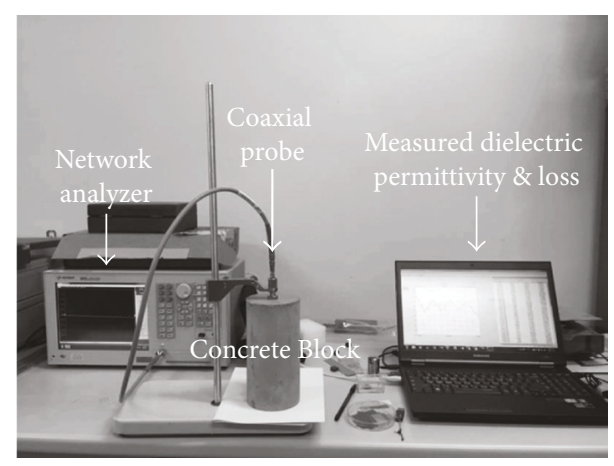

FIGURE 2: Environment of permittivity and loss tangent measurement.

constant measurement device made by Keysight Co., used in this paper, can measure the permittivity of a solid material with smooth surface as well as liquid and semisolid for a broadband frequency band from $200 \mathrm{MHz}$ to $20 \mathrm{GHz}$. In this paper, after calibrating to obtain accurate dielectric constant measurement value, we measured the dielectric constant of a solid which has already known the dielectric constant value and checked the accuracy and repeatedly measured the electrical properties of the foamed concrete. We measured and compared the dielectric constants of Teflon, wood, and soda lime glass, both of which are known for their permittivities. The results are shown in Table 2 . It can be confirmed that the measurement result is very similar to the reference value.

Cylinder shaped foamed concrete with a radius of $10 \mathrm{~cm}$ and thickness of $20 \mathrm{~cm}$ was used for the measurements, and foamed concrete with $20 \%, 40 \%$, and $60 \%$ foam without BFS was first measured. As a result, the mean permittivity at $1-8 \mathrm{GHz}$ frequency bands decreased as the foam content increased to $20 \%, 40 \%$, and $60 \%$ with values of approximately 5.24, 3.99, and 3.12 from Figure 3(a), respectively. From Figure 3(b), it can be seen that the loss tangent decreases with increasing foam content, and the loss increases with increasing frequency. Next, the permittivity and loss tangent were measured by fixing the foam content to $40 \%$ in order to investigate electrical characteristics (permittivity and loss tangent) of foamed concreted according to the BFS content. Figure 4 shows the measured results in which permittivity increases from approximately 3.99 at $0 \%$ BFS to approximately 6.12 at $60 \%$ BFS at higher BFS content, and the loss tangent also increases as the BFS content increases. As shown in Figures 3 and 4, the permittivity of the foamed concrete measured fluctuates with frequency variation because of measurement uncertainty. In this paper, the reflectance measurement method using coaxial cable, which is used to measure the dielectric properties, is unstable when an air layer is formed between the measurement probe and the surface of the measurement object. In this paper, the actual top surface of cylindrical foamed concrete has measurement uncertainty due to slight air gap between measuring probes due to slight irregularities of surface due to manufacturing tolerances.

\subsection{Electrical Modeling of Foamed Concrete for Permittivity} Calculation. To predict the effective permittivity according to the foam content and BFS content of foamed concrete, the permittivity prediction model of porous material can be modeled using (2) [21] as shown in Figure 5(b),

$$
\varepsilon_{\mathrm{eff}}=\frac{\varepsilon_{m} \varepsilon_{\mathrm{air}}(1+3 P)+3 \varepsilon_{m}^{2}(1-P)}{\varepsilon_{\mathrm{air}}(1-P)+\varepsilon_{m}(3+P)},
$$

where $\varepsilon_{\text {eff }}$ is the effective permittivity of the foamed concrete, $\varepsilon_{m}$ is the permittivity of $0 \%$ foamed concrete, $\varepsilon_{\text {air }}$ is the 


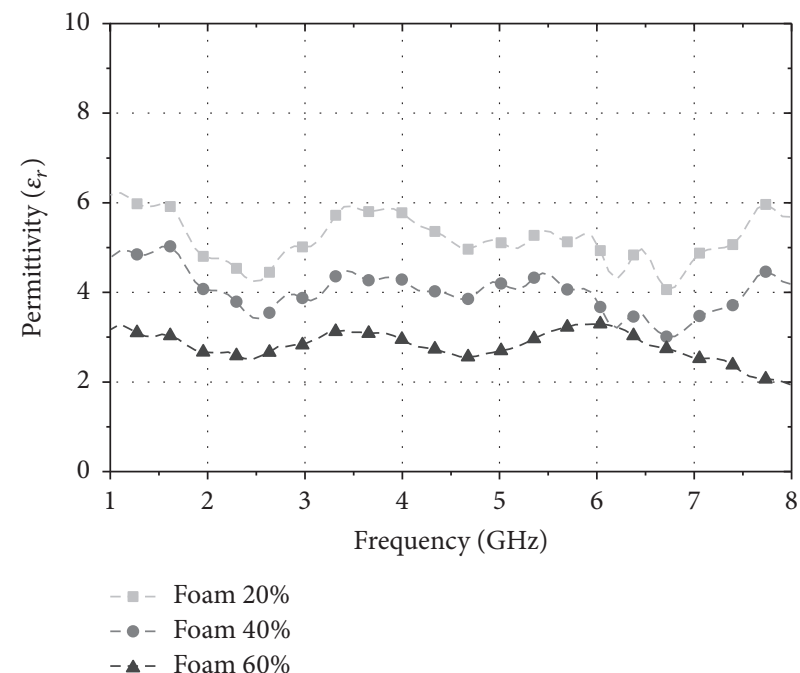

(a) Measured results of permittivity $\left(\varepsilon_{\text {eff }}\right)$

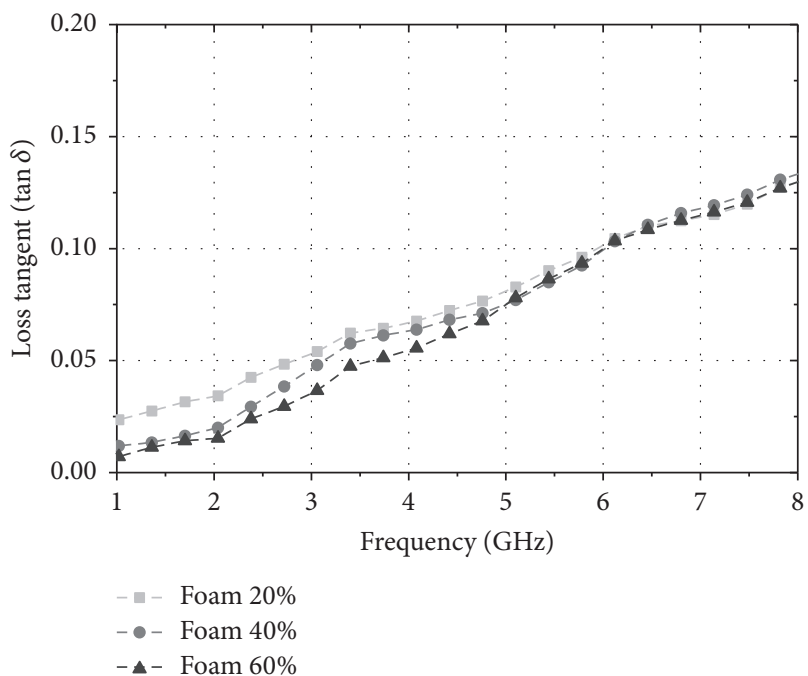

(b) Measured results of loss tangent

Figure 3: Measured results of electrical characteristics according to foam content.

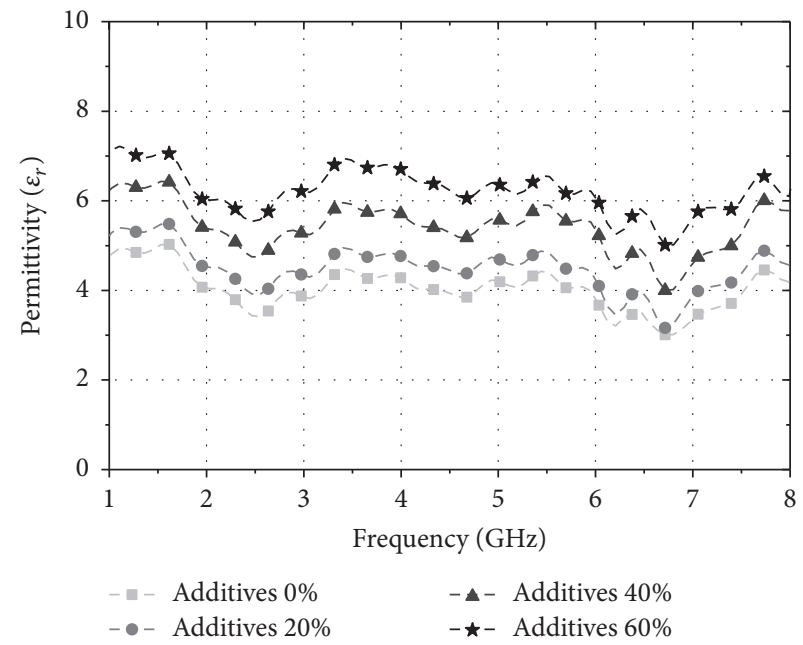

(a) Measured results of permittivity $\left(\varepsilon_{\text {eff }}\right)$

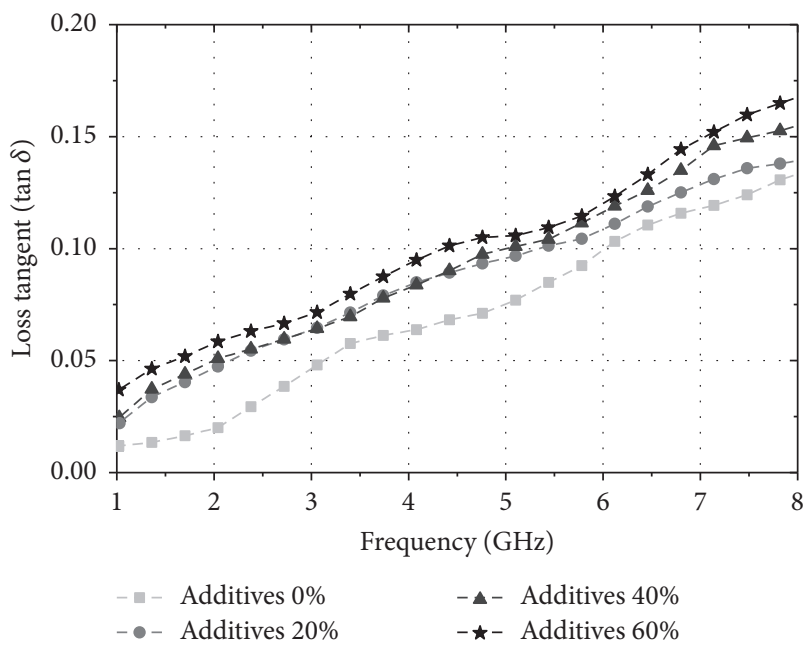

(b) Measured results of loss tangent

FIGURE 4: Measured results of electrical characteristics according to BFS content.

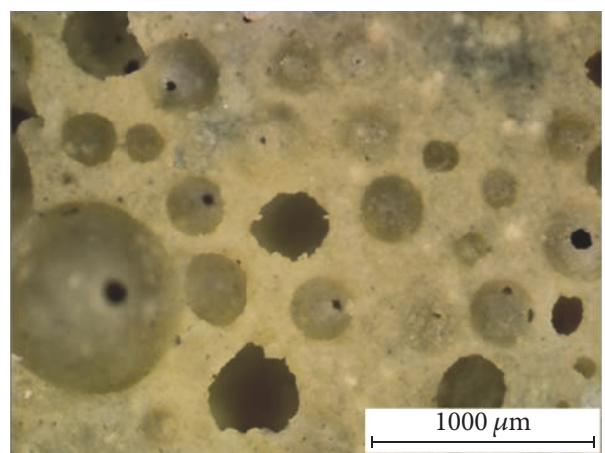

(a) Fabricated sample for permittivity measurement
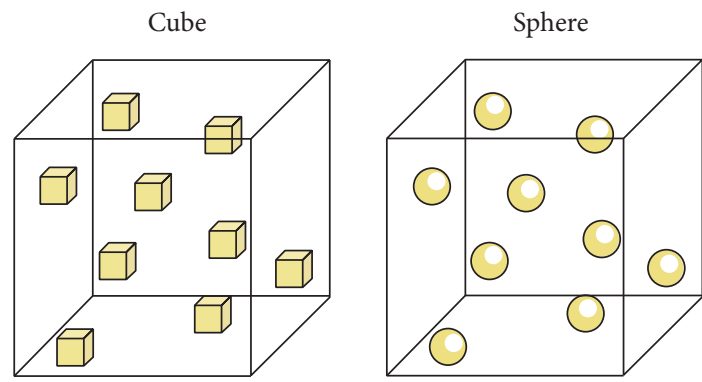

(b) Foam concrete with BFS modeling

Figure 5: Modeling of foamed concrete. 


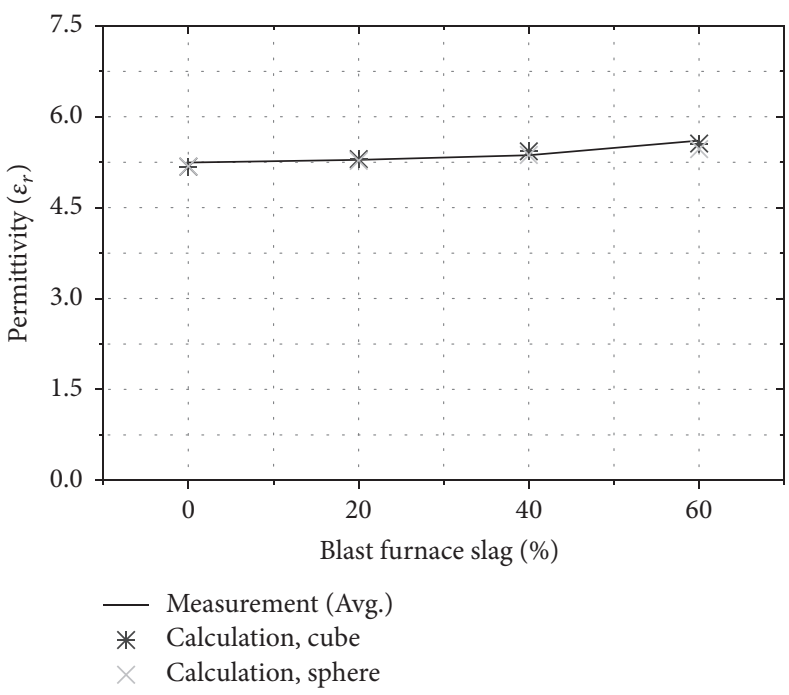

(a) Foamed concrete with $20 \%$ foam content

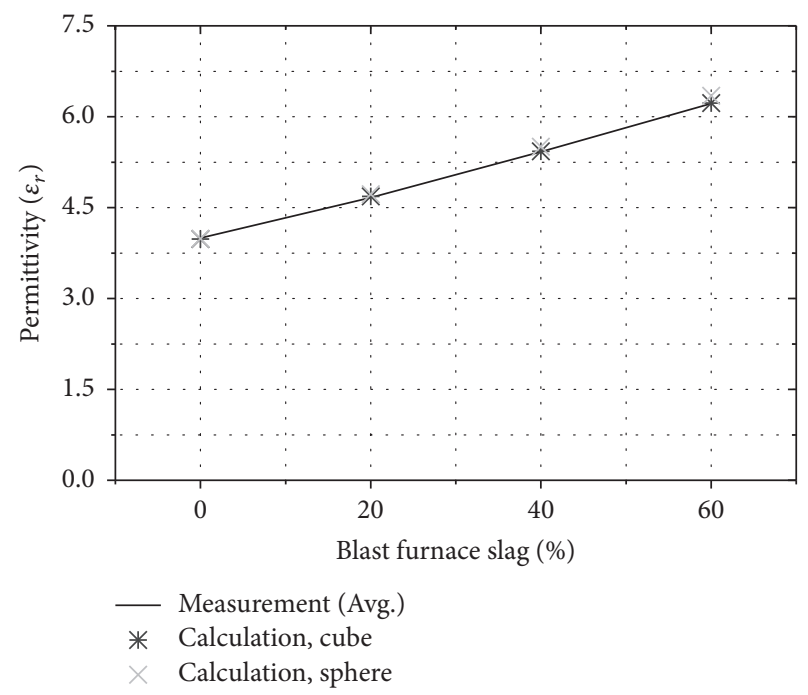

(b) Foamed concrete with $40 \%$ foam content

FIGURE 6: Comparison of calculated and measured permittivity of foamed concrete.

permittivity of air, and $P$ is the volume of the total foam of the foamed concrete. Foam is randomly generated inside the actual foamed concrete when using foaming agents and micropores generated by evaporation of remaining water after hydration also exist. BFS is added for compensation and this has effect on the concrete strength. Therefore, the content of micropores due to BFS must essentially be considered in the volume of the total foam in the foamed concrete, and the accuracy of (2) can be improved through a correction equation like

$$
P=V_{1} \times N_{1}-V_{2} \times N_{2} .
$$

Here, $V_{1}$ and $V_{2}$ are the unit volume of foam within the foamed concrete and the BFS, respectively, $N_{1}$ is the total amount of foam, and $N_{2}$ is the number of BFS.

To verify (2) that is the permittivity modeling equation according to foam and BFS in the foamed concrete, a cylinder shaped foamed concrete was manufactured as shown in Figure 5(a) and measured. Measurements and calculations of permittivity according to the foam and BFS in the foamed concrete were compared and are shown in Figure 6. The results show good agreement between calculation of modeling and measurement.

\section{Electromagnetic Shielding Simulation of Foamed Concrete}

As discussed in Section 3, the electromagnetic transmission of a material is determined by electrical properties such as dielectric constant and loss tangent of the material. To simulate the electromagnetic transmission characteristics of indoor space in the $1-8 \mathrm{GHz}$ frequency band, electrical property measurements should be used, as shown in Figures 3 and 4, depending on the foam content of the foamed concrete and the furnace slag content. In order to simulate the electromagnetic transmission of environmentally friendly foamed concrete, we confirmed the change of the electromagnetic wave transmission characteristics by using HFSS of Ansys, commercial three-dimensional electromagnetic field analysis software. In this paper, the electromagnetic transmission of $600 \times 600 \times 100 \mathrm{~mm}$ wall is estimated by applying permeability and loss tangent of $1 \sim 8 \mathrm{GHz}$ band and assuming the incident of plane wave depending on foam content and blast furnace slag content. The transmission characteristics of the simulated foamed concrete are shown in Figure 7 as the transmission loss $\left(S_{21}\right)$, which means the power ratio of the incident wave to the wave transmitted through the object. Based on $-10 \mathrm{~dB}$, electromagnetic waves were blocked above $4.9 \mathrm{GHz}$ when the foam content was $20 \%$ and electromagnetic waves were blocked above $6 \mathrm{GHz}$ when the foam content was $60 \%$. This shows that signals are better blocked at lower foam content and higher frequency. In addition, higher blocking feature is shown when more BFS is used considering the shielding characteristics according to BFS content. It can be predicted through the simulation results that the electromagnetic shielding characteristics are better when there is a higher foam content with lower BFS content.

\section{Measurements}

In order to investigate the electromagnetic shielding characteristics in indoor space when applying foamed concrete in an actual building, $60 \times 60 \mathrm{~cm}$ sized foamed concrete with a thickness of $10 \mathrm{~cm}$ was considered as the building wall, and a coaxial cable connected with a network analyzer was used. Two connected horn antennas were connected and a free space measurement method was used to investigate the electromagnetic shielding characteristics of the foamed concrete at $1-8 \mathrm{GHz}$ frequency bands, as shown in Figure 8. Similar to measuring the electrical characteristics according to the foam content of foamed concrete above, measurements 


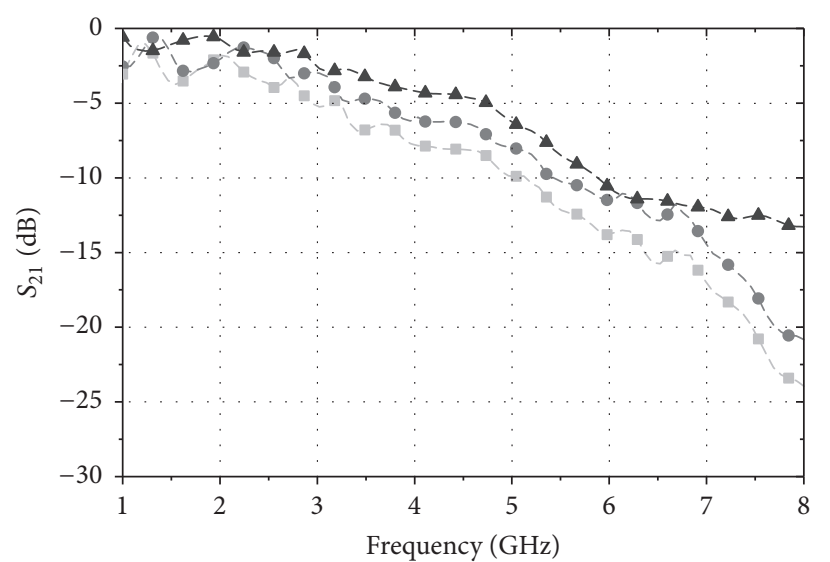

- Foam 20\%

- Foam $40 \%$

- $\Delta$ - Foam $60 \%$

(a) Simulated electromagnetic shielding according to variation of the foam content

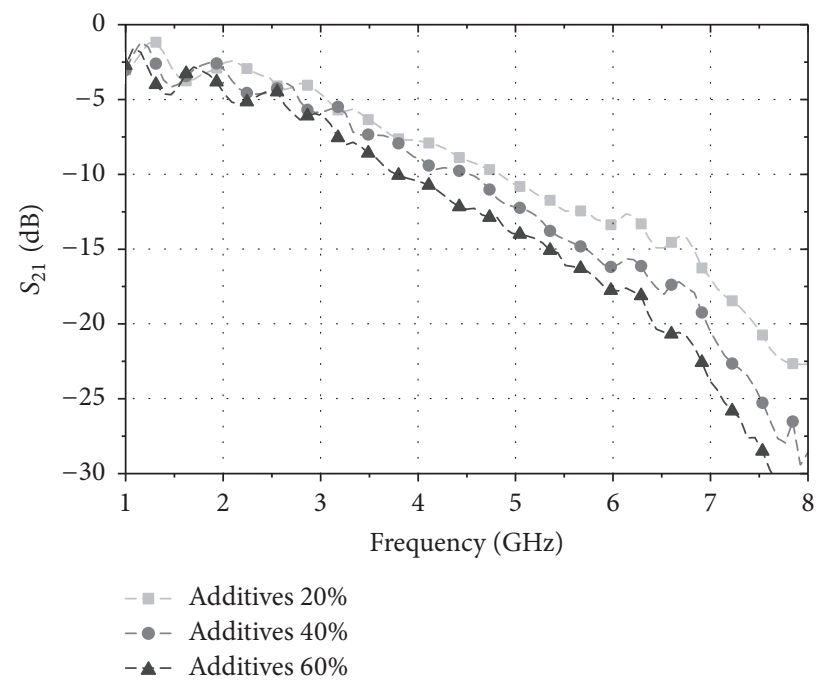

(b) Simulated electromagnetic shielding according to variation of the BFS content

FIGURE 7: Simulated results of electromagnetic shielding characteristics of foamed concrete.

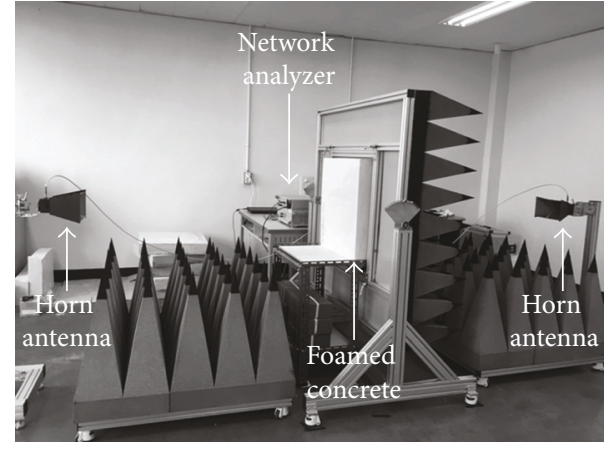

FIGURE 8: Environment of electromagnetic shielding characteristic measurement.

were conducted on three types of foamed concrete with foam of $20 \%, 40 \%$, and $60 \%$ without BFS in order to investigate the electromagnetic shielding characteristics according to foam content. Figure 9(a) shows the measured shielding characteristics according to foam content based on $-10 \mathrm{~dB}$ in which the blocking effect was observed above $3.55 \mathrm{GHz}$ when the foam content was $20 \%$ and above $4.07 \mathrm{GHz}$ when the foam content was $40 \%$. Regarding $60 \%$ foam content, the absorption characteristics are observed at $1-8 \mathrm{GHz}$ frequency bands. In addition, it can be seen in Figure 9(b) that the blocking feature is improved as the BFS content increases from $20 \%$ to $40 \%$ and $60 \%$ when the foam content is $40 \%$. Compared with the simulation results, it can be seen from the measurement results that the foam size of the foamed concrete is uneven and the difference due to the loss occurs. In addition, the measurement results of the electromagnetic wave transmission characteristics in the Figure 9 show that a signal of $-10 \mathrm{~dB}$ or more passes well at $2.4 \mathrm{GHz}$, which is the most widely used wireless LAN frequency band. This means that wireless LAN $2.4 \mathrm{GHz}$ signals may interfere with wireless LAN signals in adjacent areas in indoor space where foamed concrete is applied as a wall, which may degrade reception performance. We will study a foamed concrete wall that can improve the indoor communication performance by selectively shielding the $2.4 \mathrm{GHz}$ wireless LAN signal by applying a frequency selective surface (FSS), a spatial filter to block specific frequency bands.

\section{Conclusion}

In this paper, the electrical characteristics such as permittivity and loss tangent according to the foam and the BFS content in foamed concrete and free space measurement were used to measure the electromagnetic propagation characteristics in indoor space with functional foamed concrete as wall at $1-8 \mathrm{GHz}$ frequency bands. As a result of the measurements, electromagnetic waves penetrate at bands higher than $-10 \mathrm{~dB}$ even if the foam and the BFS contents change below $4 \mathrm{GHz}$, but signals above $4 \mathrm{GHz}$ pass when the foam content is high and the BFS content is low.

In this paper, the electromagnetic transmission characteristics of $100 \mathrm{~mm}$ thick eco-friendly foamed concrete, which can be applied to the inner walls of buildings, was measured and analyzed. The measurement results presented in this paper are expected to be used in various applications such as analysis of communication performance in indoor space and study of human influence by electromagnetic waves, and researches of foamed concrete wall with frequency selection characteristics are needed.

\section{Conflicts of Interest}

The authors declare that there are no conflicts of interest regarding the publication of this paper. 


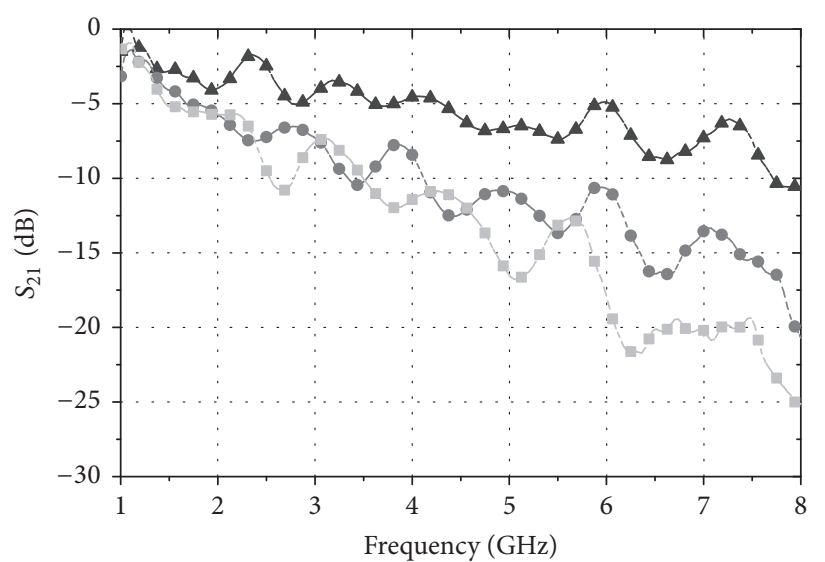

Foam $20 \%$

--๑- Foam $40 \%$

--1-- Foam 60\%

(a) Measured electromagnetic shielding according to variation of the foam content

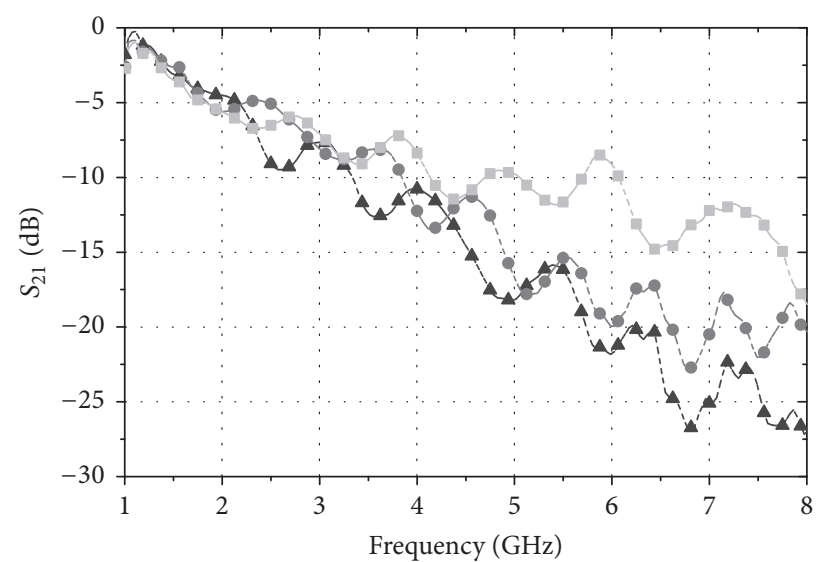

-10-- Additives 20\%

- - Additives $40 \%$

--A-- Additives 60\%

(b) Measured electromagnetic shielding according to variation of the BFS content

FIGURE 9: Measured results of electromagnetic shielding characteristics of foamed concrete.

\section{Acknowledgments}

This research was supported by Basic Science Research Program through the National Research Foundation of Korea (NRF-2015R1A2A2A01003380) and the International Science and Business Belt Program through the Ministry of Science, ICT, and Future Planning (2016K000298).

\section{References}

[1] H. H. Sung, Frequency selective wallpaper for mitigating indoor wireless interference [Ph.D. thesis], Research Space, The University of Auckland, 2006.

[2] M. Yan, S. Qu, J. Wang et al., "A miniaturized dual-band FSS with stable resonance frequencies of $2.4 \mathrm{GHz} / 5 \mathrm{GHz}$ for WLAN applications," IEEE Antennas and Wireless Propagation Letters, vol. 13, pp. 895-898, 2014.

[3] L. Subrt, P. Pechac, L. Ford, R. Langley, and J. Rigelsford, "Controlling coverage for indoor wireless networks using metalized Active FSS Walls," in Proceedings of the 19th AsiaPacific Conference on Communications (APCC '13), pp. 496-500, August 2013.

[4] B. S. Izquierdo and E. A. Park, "Dual polarized reconfigurable frequency selective surfaces," IEEE Transactions on Antennas and Propagation, vol. 62, no. 2, pp. 764-771, 2014.

[5] I. Cuinas and M. G. Sanchez, "Electromagnetic characterisation of building materials at $5.8 \mathrm{GHz}$ using transmission and reflection measurements," in Proceedings of the Antennas and Propagation Society International Symposium, vol. 1, pp. 368371, July 2000.

[6] R.-R. Lao, J.-H. Tarng, and C. Hsiao, "Transmission coefficients measurement of building materials for UWB systems in 3-10 GHz," in Proceedings of the 57th IEEE Semiannual Vehicular Technology Conference (VTC '03), pp. 11-14, April 2003.

[7] D. Micheli, A. Delfini, F. Santoni, F. Volpini, and M. Marchetti, "Measurement of electromagnetic field attenuation by building walls in the mobile phone and satellite navigation frequency bands," IEEE Antennas and Wireless Propagation Letters, vol. 14, pp. 698-702, 2015.

[8] J. Ahmadi-Shokouh, S. Noghanain, E. Hossain, M. Ostadrahimi, and J. Dietrich, "Reflection coefficient measurement for house flooring materials at 57-64 GHz," in Proceedings of the IEEE Global Telecommunications Conference (GLOBECOM '09), pp. 1-6, December 2009.

[9] H. Zhao, R. Mayzus, S. Sun et al., "28 GHz millimeter wave cellular communication measurements for reflection and penetration loss in and around buildings in New York city," in Proceedings of the IEEE International Conference on Communications (ICC '13), pp. 5163-5167, June 2013.

[10] M. Jacob, T. Kürner, R. Geise, and R. Piesiewicz, "Reflection and transmission properties of building materials in D-band for modeling future mm-wave communication systems," in Proceedings of the 4th European Conference on Antennas and Propagation (EuCAP '10), pp. 1-5, April 2010.

[11] L. Xingjun, C. Mingli, L. Yan et al., "A new absorbing foam concrete: preparation and microwave absorbing properties," Advances in Concrete Construction, vol. 3, no. 2, pp. 103-111, 2015.

[12] E. Kuzielová, L. Pach, and M. Palou, "Effect of activated foaming agent on the foam concrete properties," Construction and Building Materials, vol. 125, pp. 998-1004, 2016.

[13] H. Shin, J. Yang, Y. Yoon, and D. Mitchell, "Mix design of concrete for prestressed concrete sleepers using blast furnace slag and steel fibers," Cement and Concrete Composites, vol. 74, pp. 39-53, 2016.

[14] K.-H. Yang, K.-H. Lee, J.-K. Song, and M.-H. Gong, "Properties and sustainability of alkali-activated slag foamed concrete," Journal of Cleaner Production, vol. 68, pp. 226-233, 2014.

[15] H.-O. Shin, J.-M. Yang, Y.-S. Yoon, and D. Mitchell, "Mix design of concrete for prestressed concrete sleepers using blast furnace slag and steel fibers," Cement and Concrete Composites, vol. 74, pp. 39-53, 2016.

[16] M. R. Karim, M. F. M. Zain, M. Jamil, and F. C. Lai, "Fabrication of a non-cement binder using slag, palm oil fuel ash and rice 
husk ash with sodium hydroxide," Construction and Building Materials, vol. 49, pp. 894-902, 2013.

[17] C.-T. Chen, H.-A. Nguyen, T.-P. Chang, T.-R. Yang, and T.D. Nguyen, "Performance and microstructural examination on composition of hardened paste with no-cement SFC binder," Construction and Building Materials, vol. 76, pp. 264-272, 2015.

[18] C. J. F. Bottcher, O. V. Belle, P. Bordewijk, and A. Rip, Theory of Electric Polarization, vol. 2, Elsevier Science Ltd, 1978.

[19] F. Sagnard and G. El Zein, "Characterization of building materials for propagation modelling: frequency and time responses," AEU-International Journal of Electronics and Communications, vol. 59, no. 6, pp. 337-347, 2005.

[20] S. Yizhu, C. L. Law, and W. Dou, "Ultra-wideband measurement of the dielectric constant and loss tangent of concrete slabs," in Proceedings of the China-Japan Joint Microwave Conference (CJMW'08), pp. 537-540, IEEE, September 2008.

[21] X.-D. Liu, Z.-L. Hou, B.-X. Zhang et al., "A general model of dielectric constant for porous materials," Applied Physics Letters, vol. 108, no. 10, Article ID 102902, 2016.

[22] ECCOSTOCK, dielectric materials chart - low loss dielectrics \& other common materials, http://www.eccosorb.eu/sites/ default/files/files/dielectric-chart.pdf.

[23] G. Tesserault, N. Malhouroux, and P. Pajusco, "Multi-frequencies characterization of buildings materials: angular and polarization analysis," in Proceedings of the 2nd European Conference on Antennas and Propagation (EuCAP '07), November 2007. 


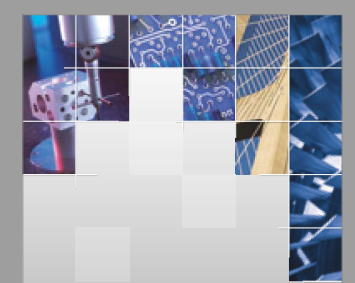

\section{Enfincering}
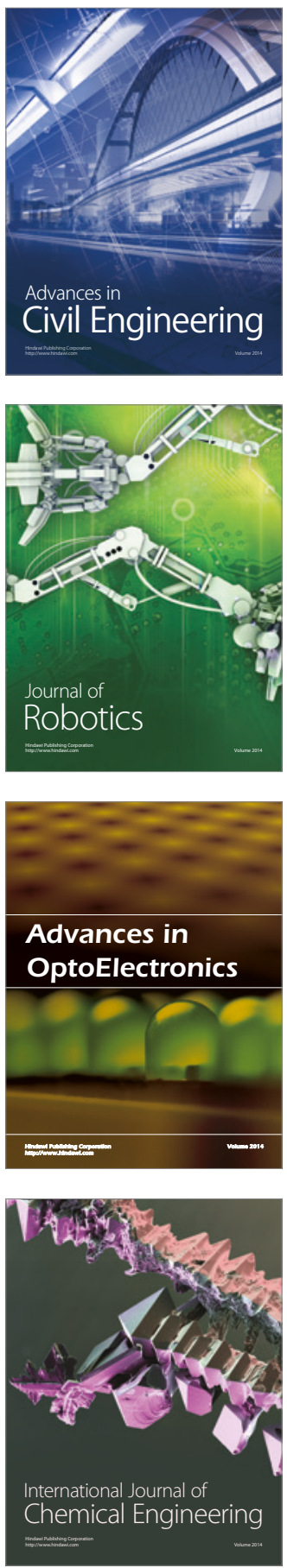

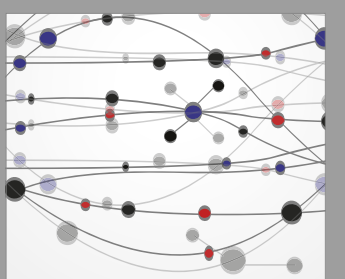

The Scientific World Journal

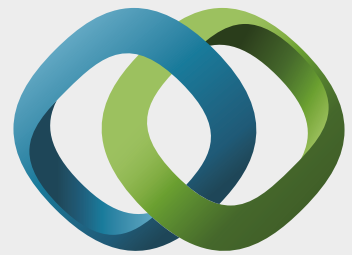

\section{Hindawi}

Submit your manuscripts at

https://www.hindawi.com
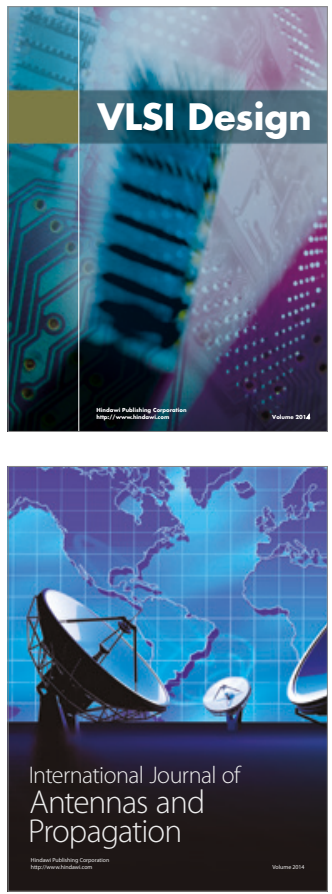

\section{Rotating}

Machinery
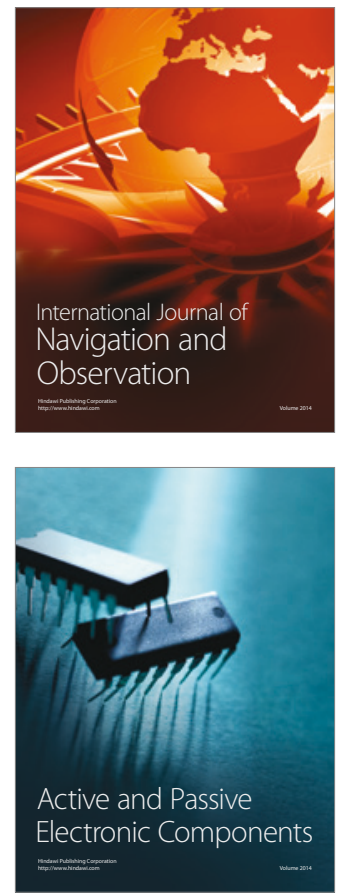
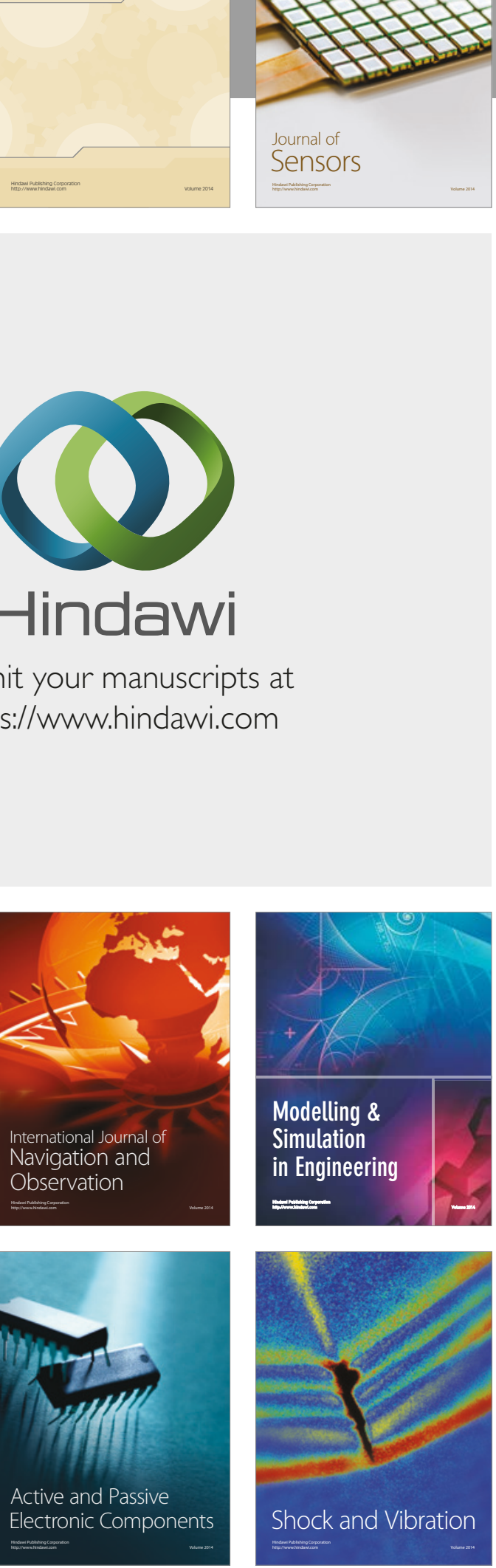
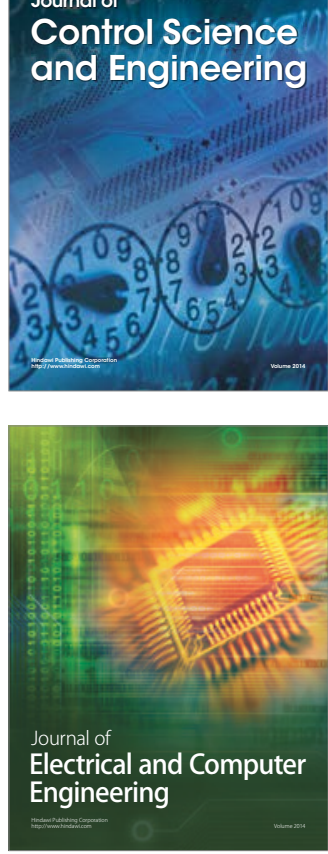

Distributed

Journal of

Control Science

and Engineering
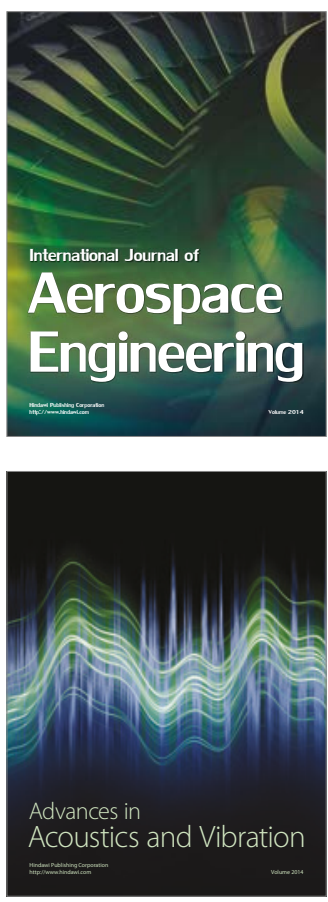

Sensor Networks 